\title{
Enhanced rhizodegradation of polycyclic aromatic hydrocarbons in corn straw-amended soil related to changing of bacterial community and functional gene expression
}

Huanyu Bao

Harbin Institute of Industry: Harbin Institute of Technology

Jinfeng Wang

Northwest Agriculture and Forestry University College of Resources and Environment

He Zhang

Northwest Agriculture and Forestry University College of Resources and Environment Jiao Li

Northwest Agriculture and Forestry University College of Resources and Environment Fuyong Wu ( $\nabla$ wfy09@163.com)

Northwest Agriculture and Forestry University College of Resources and Environment https://orcid.org/0000-0002-9566-0698

\section{Research Article}

Keywords: PAHs, Corn straw, citric acid, rhizosphere, PAH-RHDa genes

Posted Date: March 31st, 2021

DOl: https://doi.org/10.21203/rs.3.rs-332456/v1

License: (c) (i) This work is licensed under a Creative Commons Attribution 4.0 International License.

Read Full License 


\section{Abstract}

Root exudates can stimulate microbial degradation in rhizosphere, but it remains unclear whether the rhizodegradation of polycyclic aromatic hydrocarbons (PAHs) occurs in corn straw-amended soil. Hence, in the present study, either citric acid, a common low molecular weight organic acid in the root exudates, or corn straw was added into aged PAHs-contaminated soil to investigate their effectiveness in the biodegradation of PAHs. The present study showed that either corn straw $(\mathrm{Y})$ or combined application of corn straw and citric acid (YN100) significantly $(P<0.05)$ enhanced the degradation of total PAHs in soil after 28 days incubation, which increased by $8.43 \%$ and $18.62 \%$ compared with control (CK), respectively. High-throughput sequencing suggested that both $Y$ and YN100 treatments led to a shift in bacterial community in soil and increased the abundance of PAHs degraders. Interestingly, the copies of PAHs ringhydroxylating-dioxygenase (PAH-RHD) Gram-negative bacteria (GN) genes under YN100 treatment was significantly $(P<0.05)$ higher than those under $Y$ treatment in the soil. Network analysis showed that the potential hosts of PAH-RHDa genes were Lysobacter, Rhizobium, Bacillus, Devosia, Ohtaekwangia, Ramlibacter, Massilia, Steroidobacter, Phenylobacterium and Microvirga. Bacillus, Lysobacter, Rhizobium and Ohtaekwangia and all ten genera obviously increased under $\mathrm{Y}$ and YN100 treatments. These results indicate that combined application of corn straw and citric acid increased the PAH-degrading bacteria and PAH-RHDa genes, thus improving the biodegradability of PAHs in the soil. As these results verified, a combined corn straw-rhizosphere approach should be a feasible remediation strategy for PAHscontaminated soil.

\section{Introduction}

Polycyclic aromatic hydrocarbons (PAHs), some of which are mutagenic and carcinogenic benzene-ring hydrophobic aromatic pollutants, are ubiquitous and persistent in the environment (Zhang et al. 2018). It has been found that industrial site associated with petroleum refining, gas production, and the processes of coke production industries posed severe threats to the surrounding environment and human health (Jia et al. 2017). According to China soil pollution status survey in $2014,1.4 \%$ of soils were polluted by PAHs and PAHs become the second largest soil organic pollutant in China (Ministry of Ecology and Environment 2014). It is now necessary to eliminate them to reduce their negative effects on human health and ecosystem, as well as their spread to other environmental media.

Plant-bacteria interactions, in the process of phytoremediation and microbial remediation, have long been recognized as efficient and economical solution to remedy PAHs-contaminated soils through different mechanisms, especially for the soils where large areas of contamination do not require emergency remediation (Cristaldi et al. 2017; Posada-Baquero et al. 2020). During plant growth, roots secrete a myriad of root exudates (i.e. sugar, organic acids, flavonoids, amino and fatty acids, and secondary plant metabolites), which can stimulate microbial growth and increase the bioavailability of contaminants from contaminated soils (Guo et al. 2017; Jia et al. 2018). Low molecular weight organic acids (LMWOAs), for instance, citric, malic and oxalic were reportedly the main components in root exudates (Ling et al. 2009). There are reports that compared with other compounds in root exudates, LMWOAs play 
a key role in pollutant degradation (Sivaram et al. 2019). Vázquez-Cuevas et al. (2020) concluded that citric acid and malic acid could increase the desorption of phenanthrene in soil. Similarly, Gao et al. (2015) found that LMWOAs could dramatically promote the release of bound PAH residues, and citric acid has the largest release of PAHs in soil. The bioavailability of PAHs in soils could increase by desorption of LMWOAs, therefore, it may cause potential harm to ecosystems and human through specific exposure pathways.

Through this measure the increase of PAHs degraders in rhizosphere soil might enhance the degradation of PAHs desorbed by LMWOAs. As a national climate policy, crop straws were recommended to be returned to the fields to control air pollution caused by open-field burning, improve and retain the soil fertilization due to that crop returning straw to the field could enhance soil macro-aggregation, promote carbon storage, improve soil structure, and increase the richness and diversity of microbial communities (Wang et al. 2018; Liu et al. 2019; Zhou et al. 2020). China has a large agricultural output and straw producing reached $\sim 700$ million tons annually (Latifmanesh et al. 2020). Corn straw returning to the soil is increasing every year, accounting for $30.8 \%$ in northeast and north China (Wang et al. 2011; Gu et al. 2015). Numerous studies found that carbon substrate returning to soil could improve soil conditions, enhance the bioavailability of PAHs, thereby accelerating PAHs degradation in soils (Hamdi et al. 2007; Li et al. 2012; Wu et al. 2013; Garcia-Delgado et al. 2015; Sigmund et al. 2017; Wu et al. 2020). Although many studies have reported that the effect of carbon substrate or LMWOAs on the PAHs degradation in soils, there are only limited attempts to solve whether the rhizo-degradation of PAHs occurs in strawamended soils. Besides, what is needed now is further work to explore the influence of LMWOAs on the microbial communities in the rhizosphere of straw-amended soil.

Biodegradation of PAHs by bacteria mainly depends on the activities of enzymes encoded by the degradation-related genes (Zeng et al. 2017). Some dioxygenase genes involved in PAHs metabolism in bacteria have the characteristics of substrate specificity, high conservation and direct correlation with the biodegradation function of PAHs, which are regarded as indicator genes of PAHs metabolism (Baldwin et al. 2003). PAHs dioxygenase is the key enzyme of PAHs degradation, because molecular oxygen is incorporated into aromatic nucleus by multi-component aromatic RHD enzyme system in the initial step of PAHs metabolism (Cébron et al. 2008). Thus far, most researches aimed at evaluating the change of microbial communities or PAH-RHDa genes in soils contaminated by PAHs (Jurelevicius et al. 2011; Kong et al. 2018). Network analysis (NA) was widely applied to study the connection of entities and the cooccurrence patterns between genes and microbial groups, which could help us to speculate the potential host of functional genes (Barberán et al. 2012; Li et al. 2015; Zhang et al. 2020). NA was a reliable tool that offered us new insights into the antibiotic resistance genes and their potential hosts during composting process (Zhang et al. 2016; Bao et al. 2019a). However, few studies have attempted to research the co-occurrence patterns between PAH-RHDa genes and microbial taxa, which are helpful to explore the relationship between the association of bacteria and PAH-RHDa genes.

In this research, we hypothesized the increase of PAHs biodegradation in rhizosphere soil via enhancing bioavailability of PAHs by citric acid and stimulation of both microbial activity and metabolic capability 
of microorganisms added with corn straw. The aim of current research were to: (1) investigate whether combined application of corn straw and root exudates (citric acid) could enhance PAHs degradation in soils; (2) study the change of the copies of PAH-RHDa genes and microbial community structures; (3) further predict the potential PAH-RHD genes host by NA.

\section{Materials And Methods}

\section{Corn straw and soil}

A PAHs-contaminated soil at a depth of $0-20 \mathrm{~cm}$ was obtained from the surrounding of a coal-power plant with 59 years history and the detailed description of location was reported in our previous study (Bao et al., 2020). Soil pH was determined with a pH meter (water: soil $=2.5: 1, \mathrm{w} / \mathrm{v}, \mathrm{pH}=8.37$ ). The potassium dichromate volumetric method (external heating method) was used to determine the soil organic matter (SOM, $\left.15.16 \mathrm{~g} \mathrm{~kg}^{-1}\right)$. The texture of soil was classified as a sandy loam, which contains silt (58.76\%), sand (36.27\%) and clay (4.77\%). The individual PAHs concentration was shown in Table S1. The source and physicochemical properties of corn straw have been described by Bao et al. (2019). Citric acid used was of analytical purity and obtained from Sinopharm Chemical Reagent Co., Ltd of China.

\section{Pot experiments}

The indoor simulation included four treatments: without added with citric acid or corn straw (CK), added with $100 \mathrm{mg} \mathrm{kg}^{-1}$ citric acid (N100), 5\% corn straw (Y) or combined application of citric acid (100 mg kg-1) and $5 \%$ corn straw (YN100). The level of citric acid and corn straw were based on previous studies (Bao et al. 2019b; Li et al. 2019c; Vázquez-Cuevas et al. 2020). For each treatment, $200 \mathrm{~g}$ of air-dried soil was placed in a $480 \mathrm{~mL}$ plastic vial. Each treatment included triplicate and incubated at $25^{\circ} \mathrm{C}$ in dark. The water holding capacity of soil was adjusted to approximate $70 \%$. After 28 days, part of each soil sample was reserved for determination of soil PAHs, and the others were stored at $-80^{\circ} \mathrm{C}$ for soil microbial community structure and qPCR analysis.

\section{PAHs measurement}

Soxhlet extraction was performed to extract PAHs from soil and $120 \mathrm{~mL}$ of acetone and dichloromethane (DCM) mixture (1:3, v/v) were used to extract each soil sample (approximately $4.0 \mathrm{~g}$ ) according to USEPA Standard Method 3540C (USEPA 1996). The methods of sample purification and detection were same as our previous studies (Tian et al. 2017; Bao et al. 2018). High performance liquid chromatography fluorescence detector (HPLC-FLD, Shimadzu, LC-20A) equipped with an ultraviolet detector (PF-20A) and a fluorescence detector (SPD-20A) was used to determine PAHs. The HPLC system was fitted with a PAHspecific reverse column ( $\$ 4.6 \times 150-\mathrm{mm}$ Intersil ODS-P column, $5 \mu \mathrm{m}$, Shimadzu, Kyoto, Japan). A mixture of ultrapure water and methanol $(1: 1, \mathrm{v} / \mathrm{v})$ as the mobile phase and the flow rate was $0.6 \mathrm{~mL} \mathrm{~min}^{-}$

${ }^{1}$. The surrogate standard, random injection of solvent blanks and standard reference material (NIST SRM 2706 New Jersey soil) and HPLC detection limits were used as quality control. D8-Nap, d10-Ace, d10-Phe, d10-Chr, and d12- perylene was used to identify PAHs according to their relative retention time. The 
variation coefficients of $\Sigma_{15}$ PAHs concentrations (the value of acenaphthene did not detect in our soil sample) for duplicate samples were less than $10 \%$. The detection limits were 0.06 to $1.39 \mathrm{\mu g} \mathrm{kg}^{-1}$. The recoveries of surrogate standards were $80.0 \%$ for Pyr to $125 \%$ for Nap.

\section{DNA extraction and quantification of $\mathrm{PAH}-\mathrm{RHD}_{\mathrm{a}}$ gene}

Soil DNA was extracted from $0.5 \mathrm{~g}$ soil by using the E.Z.N.A.BSoil DNA Kit for soil (Omega Bio-tek, Norcross, GA, USA) following the manufacturer's instructions. The DNA solutions were stored in dark at $-20^{\circ} \mathrm{C}$ until further analysis.

PAH-RHD genes from Gram positive bacteria (GP, 642f/933r) and Gram-negative bacteria gram-negative (610f/911r) were quantified by the Real-time PCR (qPCR) on a Bio-Rad CFX96 instrument based on SYBR Green chemistry (Cébron et al. 2008). The primer pairs were described in Table S2. The detailed steps of qPCR were described in S1.

\section{Microbial community analysis}

The sequencing of 16S rRNA gene was performed at LC-Bio Technology Co., Ltd, Hang Zhou, Zhejiang Province, China. The universal primers 338F (50-ACTCCTACGGGAGGCAGCA-30) and 806R (50GGACTACHVGGGTWTCTAAT-30) was used to amplifie the V3-V4 region of the bacterial 16S rRNA. The $2 \%$ agarose gel electrophoresis was used to detect the PCR amplification products, and the AxyPrep PCR Cleanup Kit was used to recover the target fragment. The Qbit fluorescence quantification system was used to quantify the purified PCR product through a Quant-iTPicoGreendsDNA Assay Kit. IlluminaMiSeqPE300 sequencing platform was used to determine the amplified products.

\section{Data analysis}

One-way ANOVA and LSD post-hoc comparison tests, linear regression analysis and correlation analysis were conducted by SPSS 23.0. Heatmap and Circos graphs were performed using R v.4.0.1. Network analysis based on Spearman's rank correlation coefficients between PAH-RHDa genes and the bacterial communities was drawn by the Gephi (Version 0.9.2) platform.

\section{Results And Discussion}

\section{PAHs biodegradation in soils}

The degradation of PAHs was monitored after 28 days incubation of soil for all the treatments (Fig. 1). The total PAHs concentration decreased from 2275 to $1873 \mu \mathrm{g} \cdot \mathrm{kg}^{-1}$ in the CK treatment, suggesting the major contribution of degradation to PAHs by the indigenous microbes and in agreement with previous studies (Huang et al. 2019; Li et al. 2019c). There was no significant difference in the final concentration of PAHs between the CK and N100 treatment which was in line with previous studies. Li et al. (2019) demonstrated that compared to bulk soils the biodegradation efficiency of phenanthrene $(10.7 \%)$ in ryegrass rhizosphere soil was significantly increased, while not in soils added with ryegrass root 
exudates. Moreover, Vázquez-Cuevas et al. (2020) confirmed that although citric acid could promote the desorption of ${ }^{14} \mathrm{C}$-phenanthrene in soil, there is no proof that citric acid have the ability to enhance the degradation of ${ }^{14} \mathrm{C}$-phenanthrene in soils. Compared to $\mathrm{CK}, \mathrm{Y}$ treatment significantly $(P<0.05)$ increased PAHs degradation in contaminated soils. Our previous study revealed that high addition of corn straw (4\% or $6 \%$ ) enhanced the PAHs degradation in soils (Bao et al. 2019). Organic substrates could improve soil aeration and nutrient levels, as well as provide shelter for soil microorganisms, thus improving the activities of microorganism and enhancing the degradation of organic pollutants (Barathi and Vasudevan 2003). Similarly, it has been reported that returning organic substrates (sawdust, mushroom cultivation substrate, pea straw and wheat stalk) to field could stimulate the biodegradation process of PAHscontaminated soil (Huang et al. 2019; Li et al. 2012; Han et al. 2017; Koshlaf et al. 2019). Compared to other three treatments, YN100 treatment significantly decreased $(P<0.05)$ the final PAHs concentration in soil. The increase of PAHs degradation in soils could be explained from two possible perspectives. Firstly, the addition of citric acid could promote the desorption of PAHs in soil, which has been indicated by previous researches (Ling et al. 2009; Gao et al. 2015; Zhang et al. 2017). Secondly, returning corn straw to soil stimulated the growth of degraders related to the degradation of PAHs, thus may increase the biodegradation of citric acid-desorbed PAHs.

Based on the different numbers of aromatic rings, the 15 PAHs were divided into two groups, low molecular weight (LMW, 2-3 rings) PAHs and high molecular weight (HMW , 4-6 rings) PAHs. It is well known that PAHs have a strong adsorption trend to SOM and the its aqueous solubility decrease with the increase of molecular weight, which in turn decrease their bioavailability (Dachs and Eisenreich 2000). Compared with CK, N100 treatment did not increase the degradation of LMW PAHs but enhanced the HMW PAHs degradation in soils (Fig. 1). It has been reported that the effect of organic acid (oxalic acid) on the desorption of HMW PAHs in soil was greater than the LMW PAHs (Li et al. 2019c). However, when combined with corn straw, the stimulatory effect of citric acid on the dissipation of low-ring PAHs may be increased, resulting in a significant difference between YN100 and CK for LMW PAHs. Compared with CK, $\mathrm{Y}$ and YN100 treatment significantly $(P<0.05)$ enhanced HMW PAHs degradation in soil by $11.98 \%$ and 20.95, respectively. Similarly, Huang et al. (2019) concluded that adding sawdust to soils results in the higher degradation of 5-6 rings PAHs in soils than 2-4 rings PAHs. Cellulose enzymes and ligninolytic enzymes, such as laccase, manganese peroxidase and lignin peroxidase formed during the decomposition of straw have exceptional capacities for bioconversion of PAHs and may contribute to soil HMW PAHs dissipation through co-metabolic mechanisms (Li et al. 2012).

\section{The change of PAH-RHDa genes}

The abundance and composition of PAHs degradation related genes can reflect the ability of PAHs degradation in soil (Haleyur et al. 2019). The abundance of PAH-RHDa genes from Gram-positive and Gram-negative bacteria could indicate the potential of PAH degradation by soil microbial communities, mainly because the RHDa genes encode enzymes for the first step of PAH degradation, which were often used as the main biomarker to reflect the PAHs degradation in soils (Ding et al. 2010; Cébron et al. 2008). Thus, the influence of different treatments on the copies of GP or GN PAH-degrading genes was 
quantitatively studied by qPCR. The results showed that compared to GP-RHDa gene, the abundance of GN-RHDa gene was relatively high in all treatments, indicating that the degradation of PAHs by Gram negative bacteria was more active than that by Gram positive bacteria, which were consistent with previous researches. As shown in Table 1, the degradation rate of total PAHs had a significant $(P<0.05)$ positive correlation with the copies of PAH-RHD GN or PAH-RHD GP genes. Similarly, it was previously reported that PAH degradation in soils was related to the copies of PAH-RHDa genes (Ding et al. 2010; Li et al. 2019a). In addition, the PAH-RHD GN gene had a strong significant $(P<0.01)$ and positive correlation with PAH-RHD GP gene, indicating that conditions required for the two degrader populations are similar, consistent with the results of Cébron et al. (2008) for PAH-RHD GN and PAH-RHD GP degrader abundance in soils. As shown in Fig.2, both Y and YN100 significantly $(P<0.05)$ enhanced GP and GN genes copies, compared with CK and N100 treatments. In coincides with previous study, addition of mushroom cultivation substrate waste, cow manure and wheat stalk could significantly enhance the copies of pdo1 and nah genes, which were related to PAHs degradation (Han et al. 2017). Interestingly, the copies of PAH-RHDa GP and GN genes under YN100 treatment were higher than those under $\mathrm{Y}$ treatment, and especially YN100 significantly $(P<0.05)$ increased the copies of PAH-RHDa GN genes compared with $Y$ treatment. One possible reason is due to that citric acid increased the bioavailability of PAHs in soil, thus facilitating the biodegradation of PAHs via enhancing expression of PAH-RHD genes. The present study indicated that the combined addition of corn straw and citric acid is one of the effective ways to improve the abundance of PAHs degradation genes in soil. However, the abundance of PAH-RHDa genes under N100 treatment did not change significantly after 28 days incubation. This may have occurred due to that citric acid, selected as source of carbon by a highly selective bacterial community, may be utilized after 28 day incubation. Similarly, Li et al. (2019a) found that there was a minor effect of root exudates on the change of PAH-RHDa gene in soils and Wu et al. (2018) indicated the copies of PAH-RHDa genes remained stable in ryegrass rhizosphere soil.

\section{Changes in bacterial community structures}

To further understand the PAHs degradation in soils, the variation in the soil microbial community's abundance and diversity through high throughput sequencing of the soil bacteria were investigated. Principal coordinate analysis (PcOA) was applied to investigate the change of the soil bacterial community based on OTU composition under different treatments. As shown in Fig. 3, The bacterial community of CK treatment was similar to N100 treatment, but different from corn straw treatment ( $Y$ and YN100 treatment). The Fig. 4 showed the changes of bacterial communities at the phylum level in different treatments. The prevailing bacterial phylum with relative abundance more than $1 \%$ were Proteobacteria, Acidobacteria, Actinobacteria, Planctomycetes, Bacteroidetes, Chloroflexi, Firmicutes, Verrucomicrobia, WPS-1 and Gemmatimonadetes, which accounted for $97.07 \%-98.63 \%$ of the total bacterial community in soils. As shown in Fig. S2, the degradation rate of PAHs was significantly $(P<$ 0.01) positive correlation with the abundance of Proteobacteria, Bacteroidetes and Firmicutes. Proteobacteria was showed as the most dominant phyla, accounting for $49.49 \%, 48.32 \%, 28.10 \%$ and $29.75 \%$ under Y, YN100, CK and N100 treatment, respectively. Previous studies indicated that Alphaproteobacteria, Gammaproteobacteria and Betaproteobacteria were found to be the potential 
bioindicator of PAHs in soils (Martin et al. 2012; Niepceron et al. 2013; Li et al. 2019b). In addition, Firmicutes and Bacteroidetes have been reported to show great potential for PAHs degradation (Zhu et al. 2017; Guo et al. 2020). The present results indicated that Alphaproteobacteria, Gammaproteobacteria and Betaproteobacteria were the dominant classes under $\mathrm{Y}$ or YN100 treatments, which is similar with Koshlaf et al. (2019). What's more, the abundance of Firmicutes and Bacteroidetes under $Y$ and YN100 treatments were much higher than those under CK and N100 treatment, suggesting the higher degradation potential of PAHs under $\mathrm{Y}$ and YN100 treatments.

\section{Changes in PAH-related degrading genus}

High-throughput sequencing mainly focused on the structure of the bacterial communities in soils. However, it is hard to find the change of the bacteria genus related to PAHs degradation. In this research, network analysis was used to analyze the relationship between microbial community and PAH-RHDa genes and determine the possible hosts of PAH-RHDa genes. As shown in Fig. 5, the potential hosts of PAH-RHDa genes were Lysobacter, Rhizobium, Bacillus, Devosia, Ohtaekwangia, Ramlibacter, Massilia, Steroidobacter, Phenylobacterium and Microvirga. It is reported that Ohtaekwangia, Bacillus, Lysobacter and Rhizobium had the ability to degrade PAHs (Bao et al. 2020). Devosia was abundant in crude oil and might play important roles in the degradation of asphaltene in soils (Song et al. 2018). In addition, Massilia, Phenylobacterium and Steroidobacter were regarded as key genera for PAHs degradation in soils (Li et al. 2019c; Cebron et al. 2015; Huang et al. 2019). However, there is currently no information on the role of Ramlibacter and microvriga for PAH degradation, because it has not been reported to be associated with PAHs degradation, and their roles in PAH contaminated soil are still unclear.

The changes in the relative abundances of PAHs bacteria at genus level were shown in Fig. 6. Some PAHs degraders were higher under CK and N100 treatments, such as Lysobacter, Ohtaekwangia and Steroidobacter. However, the primary genera under Y and YN100 treatments were Lysobacter, Rhizobium, Bacillus and Devosia. The ten genera referred had significantly $(P<0.05)$ correlated with the degradation rate of HMW PAHs ( $r=0.725-0.834)$ and total PAHs ( $r=0.708-0.835)$, respectively (Fig. S1). Compared with $\mathrm{CK}$, the abundance of ten genera related to PAH degradation were significantly $(P<0.05)$ increased in $Y$ and YN100 treatments, indicating that the significant increase biodegradation of total PAHs and HMW PAHs might be related to increase of PAHs-degrading bacteria. However, there was no significantly difference in the abundance of bacterial genera related to PAHs degradation between CK and N100 treatments. Consequently, this may be due to that the degradation rate of PAHs was low in soil treated with citric acid.

\section{Proposed degradation mechanism of PAHs in YN100 treatment}

The highest degradation rate of PAHs was found in soil under YN100 treatment than other three treatments. Fig. 7 illustrates the potential degradation mechanism of PAHs added with citric acid and corn straw. Citric acid facilitated the desorption of PAHs in soils, which indicated by previous researches (Zhu et al. 2009; Jia et al. 2016). Corn straw increased soil nutrients and improved soil aeration condition, 
which was beneficial to enhance the PAH-degrading bacterial biomass in PAH-contaminated soil. Citric acid-desorbed PAHs was degraded by PAHs degraders via increase the expression of PAH-RHDa genes.

\section{Conclusions}

In the present study, the possibility of rhizo-degradation of PAHs occuring in corn straw-amended soil was explored. In addition, qPCR and high throughput sequencing analysis were applied to investigate the change of PAH-RHDa genes and the bacterial community composition in soil under different treatments. Combined application of corn straw and citric acid significantly increased the degradation efficiency of PAHs, but citric acid alone offers a slight contribution to accelerate PAHs degradation in soil. The increased biodegradation of PAHs under YN100 treatment might be related to the fact that citric acid improved the mobility and solubility of PAHs in soils and that corn straw addition increased the copies of PAH-degrading genes and abundance of PAHs degraders. On the whole, the present study provided fundamental insights into the rhizo-degradation of PAHs in corn straw-amended soil. Further study to investigate the changing of PAHs bioavailability treated with corn straw and citric acid will contribute to a better understanding of the potential mechanisms of this soil system for the degradation of PAHs.

\section{Declarations}

Authors' contributions Huanyu Bao: Methodology, Investigation, Software, Data curation, Formal analysis, Writing-Original Draft. Jinfeng Wang: Methodology, Investigation, Software, Data curation, Formal analysis, Writing-Original Draft. He Zhang: Investigation. Jiao Li: Investigation. Fuyong Wu: Conceptualization, Methodology, Resources, Supervision, Funding acquisition, Project administration, Writing-review \& editing.

Funding This work was supported by the financial support from National Natural Science Foundation of China $(42077325 ; 41571456)$ and the Natural Science Basic Research Plan in Shaanxi Province of China (2019JZ-25).

Data availability The authors declare that all relevant data supporting the findings of this study are included in this article and its supplementary information files.

\section{Compliance with ethical standards}

Ethical approval and consent to participate Not applicable.

Consent for publication Not applicable.

Competing interests The authors declare that they have no competing interests.

\section{References}


Bao HY, Hou SW, Niu H, Tian K, Liu XP, Wu FY (2018) Status, sources, and risk assessment of polycyclic aromatic hydrocarbons in urban soils of Xi'an, China. Environ Sci Pollut Res 25:18947-18959.

Bao HY, Wang JF, Li J, Zhang H, Wu FY (2019b) Effects of corn straw on dissipation of polycyclic aromatic hydrocarbons and potential application of backpropagation artificial neural network prediction model for PAHs bioremediation. Ecotox Environ Safe 186:109745.

Bao JF, Wang XJ, Gu J, Dai XX, Zhang KY, Wang QZ, Ma JY, Peng HL (2019a) Effects of macroporous adsorption resin on antibiotic resistance genes and the bacterial community during composting. Bioresource Technol 295:121997.

Bao HY, Wang JF, Zhang H, Li J, Li H, Wu FY (2020) Effects of biochar and organic substrates on biodegradation of polycyclic aromatic hydrocarbons and microbial community structure in PAHscontaminated soils. J Hazard Mater 385:121595.

Baldwin BR, Nakatsu CH, Nies L (2003) Detection and enumeration of aromatic oxygenase genes by multiplex and real-time PCR. Appl Environ Microbiol 69:3350-3358.

Barathi S, Vasudevan N (2003) Bioremediation of Crude Oil Contaminated Soil by Bioaugmentation of Pseudomonas fluorescens NS1. J Environ Sci Health Part A 38:1857-1866.

Barberán A, Bates ST, Casamayor EO, Fierer N (2012) Using network analysis to explore co-occurrence patterns in soil microbial communities. ISME J 6:343-351.

Cébron A, Norini MP, Beguiristain T, Leyval C (2008) Real-Time PCR quantification of PAH-ring hydroxylating dioxygenase (PAH-RHDa) genes from Gram positive and Gram negative bacteria in soil and sediment samples. J Microbiol Meth 73:48-159.

Cebron A, Beguiristain T, Bongoua-Devisme J, Denonfoux J, Faure P, Lorgeoux C, Ouvrard S, Parisot N, Peyret P, Leyval C (2015) Impact of clay mineral, wood sawdust or root organic matter on the bacterial and fungal community structures in two aged PAH-contaminated soils. Environ Sci Pollut Res 22:1372413738.

Cristaldi A, Conti GO, Jho EH, Zuccarello P, Grasso A, Copat C, Ferrante M (2017) Phytoremediation of contaminated soils by heavy metals and PAHs. A brief review. Environ Technol Inno 8:309-326.

Dachs J, Eisenreich SJ (2000) Adsorption onto aerosol soot carbon dominates gas-particle partitioning of polycyclic aromatic hydrocarbons. Environ Sci Technol 34:3690-3697.

Ding GC, Heuer H, Zuhlke S, Spiteller M, Pronk GJ, Heister K, Kogel-Knabner I, Smalla K (2010) Soil typedependent responses to phenanthrene as revealed by determining the diversity and abundance of polycyclic aromatic hydrocarbon ringhydroxylating dioxygenase genes by using a novel PCR detection system. Appl Environ Microb 76:4765-4771. 
Gao YZ, Yuan XJ, Lin XH, Sun BQ, Zhao Z.H (2015) Low-molecular-weight organic acids enhance the release of bound PAH residues in soils. Soil Till Res 145:103-110.

Garcia-Delgado C, Alfaro-Barta I, Eymar E (2015) Combination of biochar amendment and mycoremediation for polycyclic aromatic hydrocarbons immobilization and biodegradation in creosotecontaminated soil. J Hazard Mater 285:259-266.

Gu YF, Zhang T, Che H, Lu XX, Du YQ (2015) Influence of returning corn straw to soil on soil nematode communities in winter wheat. Acta Ecologica Sinica 35:52-56.

Guo MX, Gong ZQ, Miao R, Su D, Li XJ, Jia XY, Zhuang J (2017) The influence of root exudates of maize and soybean on polycyclic aromatic hydrocarbons degradation and soil bacterial community structure. Ecol Eng 99:22-30.

Guo YL, Zhao QY, Yang SC, Wang HQ, Qiao PW, Song Y, Cheng YJ, Li PZ (2020) Removal of polycyclic aromatic hydrocarbons (PAHs) and the response of indigenous bacteria in highly contaminated aged soil after persulfate oxidation. Ecotox Environ Safe 190:110092.

Haleyur N, Shahsavari E, Jain SS, Koshlaf E, Ravindran VB, Morrison PD, Osborn AM, Ball AS (2019) Influence of bioaugmentation and biostimulation on PAH degradation in aged contaminated soils: Response and dynamics of the bacterial community. J Environ Manage 238:9-58.

Hamdi H, Benzarti S, Manusadz `ianas L, Aoyama I, Jedidi N (2007) Bioaugmentation and biostimulation effects on PAH dissipation and soil ecotoxicity under controlled conditions. Soil Biol Biochem 39:19261935.

Han XM, Hu HW, Shi XZ, Zhang LM, He JZ (2017) Effects of different agricultural wastes on the dissipation of PAHs and the PAH-degrading genes in a PAHcontaminated soil. Chemosphere 172:1286293.

Huang YJ, Pan H, Wang QL, Ge YY, Liu WX, Christie P (2019) Enrichment of the soil microbial community in the bioremediation of a petroleum-contaminated soil amended with rice straw or sawdust. Chemosphere 224:265-271.

Jia H, Lu HL, Dai MY, Hong HL, Liu JC, Yan CL (2016) Effect of root exudates on sorption, desorption, and transport of phenanthrene in mangrove sediments. Mar Pollut Bull 109:171-177.

Jia HZ, Zhao S, Nulaji G, Tao KL, Wang F, Sharma VK, Wang CY (2017) Environmentally Persistent Free Radicals in Soils of Past Coking Sites: Distribution and Stabilization. Environ Sci Technol 51:6000-6008.

Jia H, Hou DY, Dai MY, Lu HL, Yan CL (2018) Effects of root exudates on the mobility of pyrene in mangrove sediment-water system. Catena 162:396-401. 
Jurelevicius D, Alvarez VM, Peixoto R, Rosado AS, Seldin L (2011) Bacterial polycyclic aromatic hydrocarbon ring-hydroxylating dioxygenases (PAH-RHD) encoding genes in different soils from King George Bay, Antarctic Peninsula. Appl Soil Ecol 55:1-9.

Kong FX, Sun GD, Liu ZP (2018) Degradation of polycyclic aromatic hydrocarbons in soil mesocosms by microbial/plant bioaugmentation: Performance and mechanis. Chemosphere 198:83-91.

Koshlaf E, Shahsavari E, Haleyur N, Osborn AM, Ball AS (2019) Eff ;ect of biostimulation on the distribution and composition of the microbial community of a polycyclic aromatic hydrocarboncontaminated landfill soil during bioremediation. Geoderma 338:216-225.

Latifmanesh H, Deng AX, Li L, Chen ZJ, Zheng YT, Bao XT, Zheng CY, Zhang WJ (2020) How incorporation depth of corn straw affects straw decomposition rate and C\&N release in the wheat-corn cropping system. Agr Ecosyst Environ 300:107000.

Li XZ, Wu YC, Lin XG, Zhang J, Zeng J (2012) Dissipation of polycyclic aromatic hydrocarbons (PAHs) in soil microcosms amended with mushroom cultivation substrate. Soil Biol Biochem 47:91-197.

Li B, Yang Y, Ma LP, Ju F, Guo F, Tiedje JM, Zhang T (2015) Metagenomic and network analysis reveal wide distribution and co-occurrence of environmental antibiotic resistance genes. ISME J 9:2490-2502.

Li JB, Luo CL, Zhang DY, Cai XX, Jiang LF, Zhao X, Zhang G (2019a) Diversity of the active phenanthrene degraders in PAH-polluted soil is shaped by ryegrass rhizosphere and root exudates. Soil Biol Biochem 128:100-110.

Li XN, Qu CS, Bian YR, Gu CG, Jiang X, Song Y (2019b) New insights into the responses of soil microorganisms to polycyclic aromatic hydrocarbon stress by combining enzyme activity and sequencing analysis with metabolomics. Environ Pollut 255:113312.

Li XN, Song Y, Wang F, Bian YR, Jiang X (2019c) Combined effects of maize straw biochar and oxalic acid on the dissipation of polycyclic aromatic hydrocarbons and microbial community structures in soil: a mechanistic study. J Hazard Mater 364:325-331.

Ling WT, Ren LL, Gao YZ, Zhu XZ, Sun BQ (2009) Impact of low-molecular-weight organic acids on the availability of phenanthrene and pyrene in soil. Soil Biol Biochem 41:2187-2195.

Liu X, Zhou F, H GQ, Shao S, He HB, Zhang W, Zhang XD, Li LJ (2019) Dynamic contribution of microbial residues to soil organic matter accumulation influenced by maize straw mulching. Geoderma 333:35-42.

Martin F, Stéphane T, Paslier DL, Barbance A, Martin-Laurent F, Bru D, Geremia R, Blake G, Jouanneau Y (2012) Betaproteobacteria dominance and diversity shifts in the bacterial community of a PAHcontaminated soil exposed to phenanthrene. Environ Pollut 162:345-353. 
Ministry of Ecology and Environment (2014) http://news.xinhuanet.com/politics/201404/17/c110291606.htm. Accessed 17 April 2014

Niepceron M, Martin-Laurent F, Crampon M, Portet-Koltalo F, Akpa-Vinceslas M, Legras M, Bru D, Bureau F, Bodilis J (2013) GammaProteobacteria as a potential bioindicator of a multiple contamination by polycyclic aromatic hydrocarbons (PAHs) in agricultural soils. Environ Pollut 180:199-205.

Posada-Baquero R, Jimenez-Volkerink SN, García JL, Vila J, Cantos M, Grifoll M, Ortega-Calvo JJ (2020) Rhizosphere-enhanced biosurfactant action on slowly desorbing PAHs in contaminated soil. Sci Total Environ 720:137608.

Sigmund G, Poyntner C, Pinar G, Kah M, Hofmann T (2017) Influence of compost and biochar on microbial communities and the sorption/degradation of PAHs and NSO-substituted PAHs in contaminated soils. J Hazard Mater 345:107-113.

Sivaram AK, Logeshwaran P, Lockington R, Naidu R, Megharaj M (2019) Low molecular weight organic acids enhance the high molecular weight polycyclic aromatic hydrocarbons degradation by bacteria. Chemosphere 222:132-140.

Song WF, Wang JW, Yan YC, An LY, Zhang F, Wang L, Xu Y, Tian MZ, Nie Y, Wu XL (2018) Shifts of the indigenous microbial communities from reservoir production water in crude oil- and asphaltene-degrading microcosms. Int Biodeter Biodegr 132:18-29.

Tian K, Bao HY, Zhang XC, Shi TR, Liu XP, Wu FY (2017) Residuals, bioaccessibility and health risk assessment of PAHs in winter wheat grains from areas influenced by coal combustion in China. Sci Total Environ 618:777-784.

USEPA (1996) Method 3540C: Soxhlet Extraction. US Environmental Protection Agency. Washington, DC.

Vázquez-Cuevas GM, Lag-Brotons AJ, Ortega-Calvo JJ, Stevens CJ, Semple KT (2020) The effect of organic acids on the behaviour and biodegradation of 14C-phenanthrene in contaminated soil. Soil Biol Biochem 143:107722.

Wang RF, Zhang JW, Dong ST, Liu P (2011) Present situation of maize straw resource utilization and its effect in main maize production regions of China. Chin J Appl Ecol 22:1504-1510 (in Chinese).

Wang XJ, Jia ZK, Liang LY, Zhao YF, Yang BP, Ding RX, Wang JP, Nie JF (2018) Changes in soil characteristics and maize yield under straw returning system in dryland farming. Field Crop Res 218:1117.

Wu GZ, Kechavarzi C, Li XG, Sui H, Pollard SJT, Coulon F (2013) Influence of mature compost amendment on total and bioavailable polycyclic aromatic hydrocarbons in contaminated soils. Chemosphere 90:2240-2246. 
Wu YC, Ding QM, Zhu QH, Zeng J, Ji R, Dumont MG, Lin XG (2018) Contributions of ryegrass, lignin and rhamnolipid to polycyclic aromatic hydrocarbon dissipation in an arable soil. Soil Biol Biochem 118:2734.

Wu ML, Guo XQ, Wu JL, Chen KL (2020) Effect of compost amendment and bioaugmentation on PAH degradation and microbial community shifting in petroleum-contaminated soil. Chemosphere 256:126998.

Zeng J, Zhu QH, Wu YC, Chen H, Lin XG (2017) Characterization of a polycyclic aromatic ringhydroxylation dioxygenase from Mycobacterium sp. NJS-P. Chemosphere 185:67-74.

Zhang JY, Chen MX, Sui QW, Tong J, Jiang C, Lu XT, Zhang YX, Wei YS (2016) Impacts of addition of natural zeolite or a nitrification inhibitor on antibiotic resistance genes during sludge composting. Water Res 91:339-349.

Zhang YN, Yang XL, Gu CG, Bian YR, Liu ZT, Jia MY, Wang F, Wang DZ, Jiang X (2017) Prediction of Polycyclic Aromatic Hydrocarbon Bioaccessibility to Earthworms in Spiked Soils by Composite Extraction with Hydroxypropyl-ß-Cyclodextrin and Organic Acids. Pedosphere 27:502-510.

Zhang GX, Guo XF, Zhu YE, Liu XT, Han ZW, Sun K, Ji L, He QS, Han LF (2018) The effects of different biochars on microbial quantity, microbial community shift, enzyme activity, and biodegradation of polycyclic aromatic hydrocarbons in soil. Geoderma 328:100-108.

Zhang GJ, Guan YT, Zhao RX, Feng J, Huang J, Ma LP, Li B (2020) Metagenomic and network analyses decipher profiles and co-occurrence patterns of antibiotic resistome and bacterial taxa in the reclaimed wastewater distribution system. J Hazard Mater 400:123170.

Zhou GP, Cao WD, Bai JS, Xu CX, Zeng NH, Gao SJ, Rees RM, Dou FG (2020) Co-incorporation of Rice Straw and Leguminous Green Manure Can Increase Soil Available N and Reduce C and N Losses: an Incubation Study. Pedosphere 30:661-670.

Zhu YH, Zhang SZ, Huang HL, Wen B (2009) Effects of maize root exudates and organic acids on the desorption of phenanthrene from soils. J Environ Sci 21:920-926.

Zhu FX, Storey S, Ashaari MM, Clipson N, Doyle E (2017) Benzo(a)pyrene degradation and microbial community responses in composted soil. Environ Sci Pollut Res 24:5404-5414.

\section{Table 1}

Table 1 Correlation coefficients ( $r$ ) among the removal rate of LMW PAHs, HMW PAHs, Total PAHs and PAH-RHD $\alpha$ genes. 


\begin{tabular}{lccccc}
\hline & LWM PAHs & HMW PAHs & Total PAHs & PAH-RHD GN PAH-RHD GP \\
\hline LWM PAHs & 1.000 & & & & \\
HMW PAHs & $0.595^{*}$ & 1.000 & & & \\
Total PAHs & $0.716^{* *}$ & $0.987^{* *}$ & 1.000 & \\
PAH-RHD GN & $0.628^{*}$ & $0.912^{* *}$ & $0.917^{* *}$ & 1.000 & \\
PAH-RHD GP & 0.507 & $0.853^{* *}$ & $0.842^{* *}$ & $0.962^{* *}$ & 1.000 \\
\hline
\end{tabular}

*Correlation is significant at the 0.05 level (2-tailed)

** Correlation is significant at the 0.01 level (2-tailed)

Figures

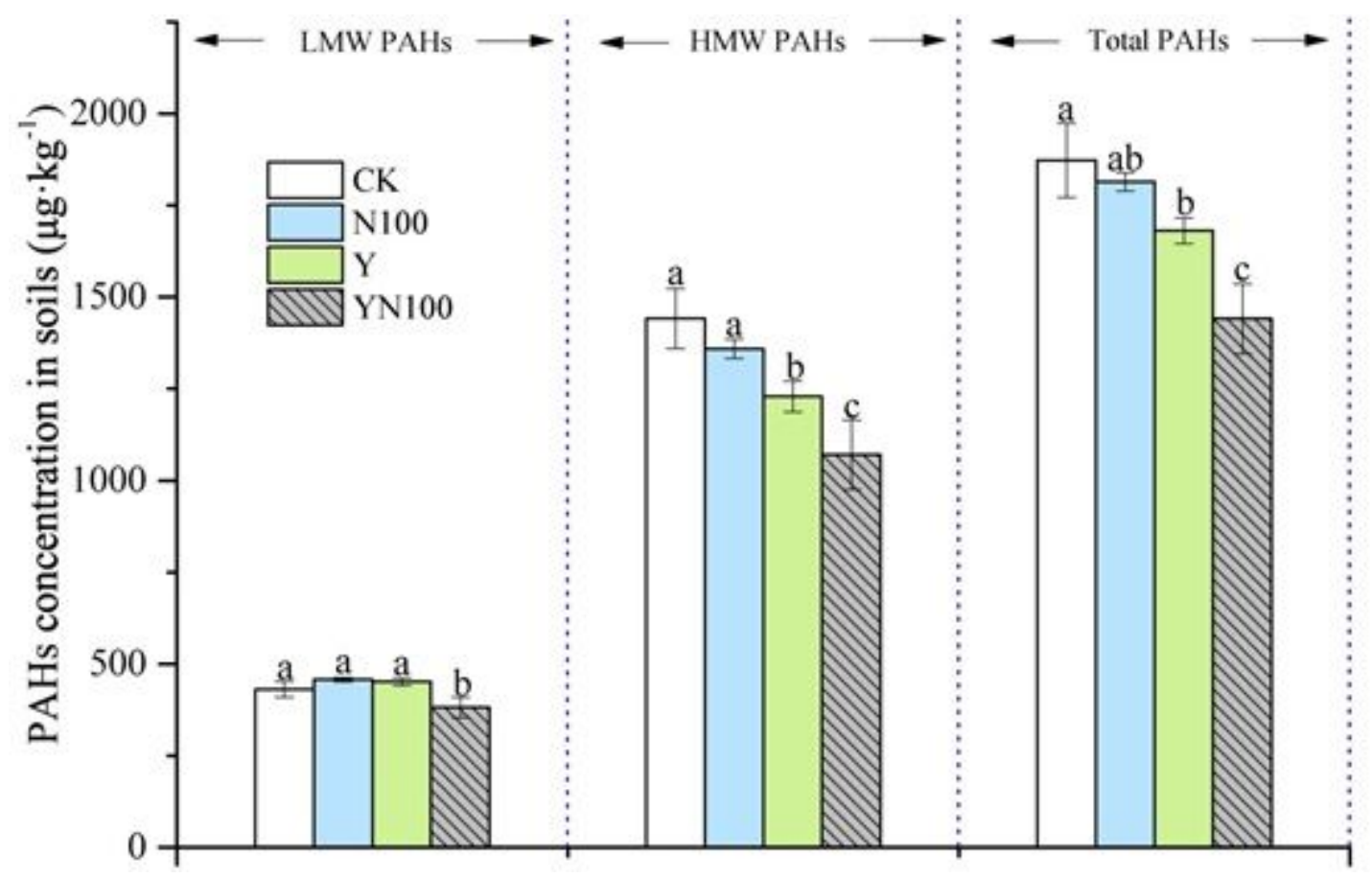

\section{Figure 1}

Concentration of LMW PAHs, HMW PAHs and Total PAHs in PAHs-contaminated soils under different treatments after 28 days of incubation. CK: no citric acid and no corn straw addition; N100: soil amended with $100 \mathrm{mg} \cdot \mathrm{kg}-1$ citric acid; Y: soil amended with $5 \%$ corn straw; YN100: soil amended with $5 \%$ corn straw and $100 \mathrm{mg} \cdot \mathrm{kg}-1$ citric acid. Bars marked with different letter are significantly $(p<0.05)$ different among different amendment treatments according to least significant difference (LSD) test (mean \pm SD, $n=3)$. 


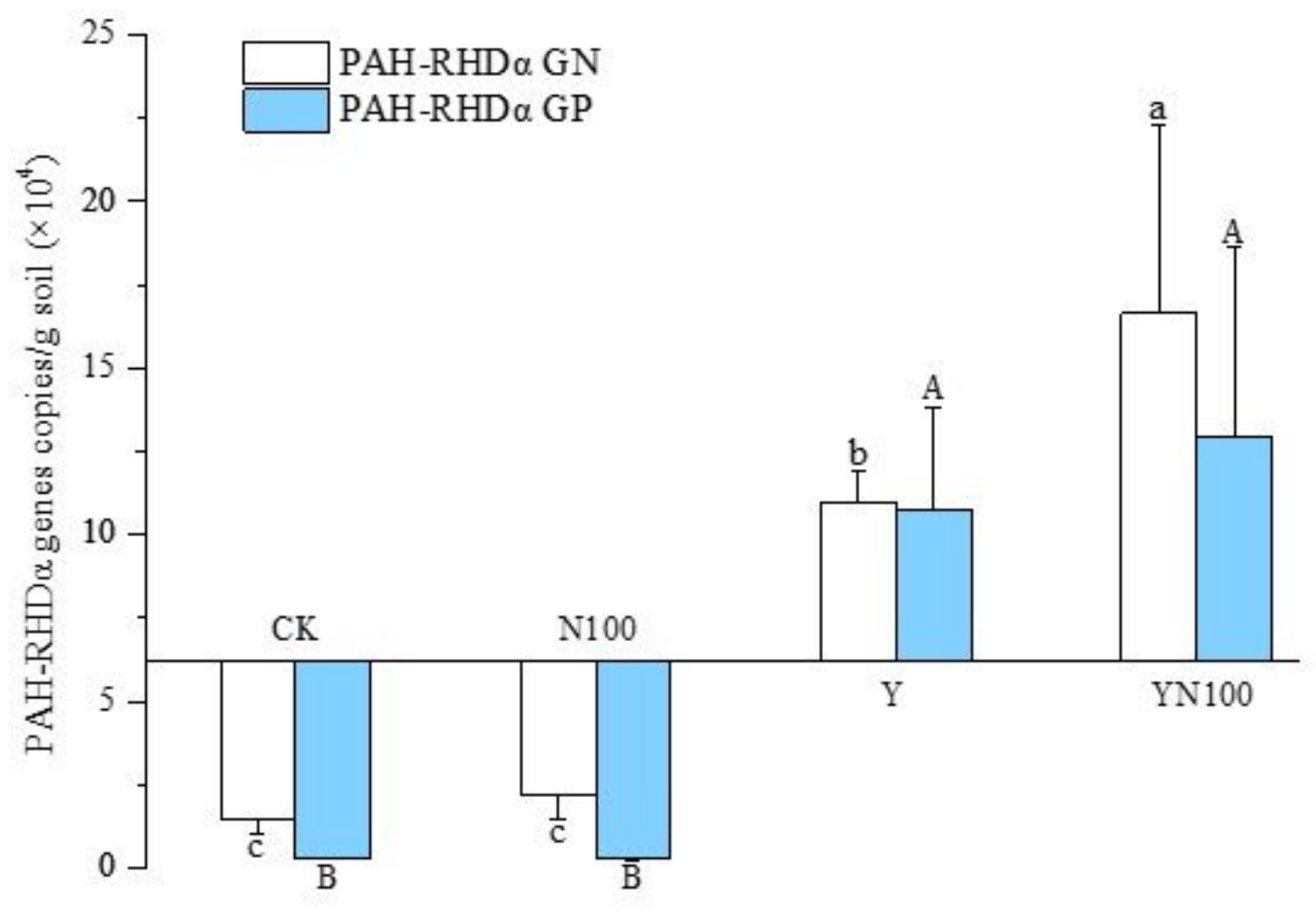

Figure 2

Variation in abundance of PAH-RHDa genes numbers detected by quantitative PCR in PAHs-contaminated soils under different treatments after 28 days of incubation. Data are expressed as the mean \pm standard deviation of three replicated treatments. Different uppercase and lowercase letters indicate significant differences of PAH-RHDa GN genes copies and PAH-RHDa GP genes copies among different treatments. CK: no citric acid and no corn straw addition; N100: soil amended with $100 \mathrm{mg} \cdot \mathrm{kg}-1$ citric acid; Y: soil amended with $5 \%$ corn straw; YN100: soil amended with $5 \%$ corn straw and $100 \mathrm{mg} \cdot \mathrm{kg}-1$ citric acid. 


\section{PCoA Analysis}

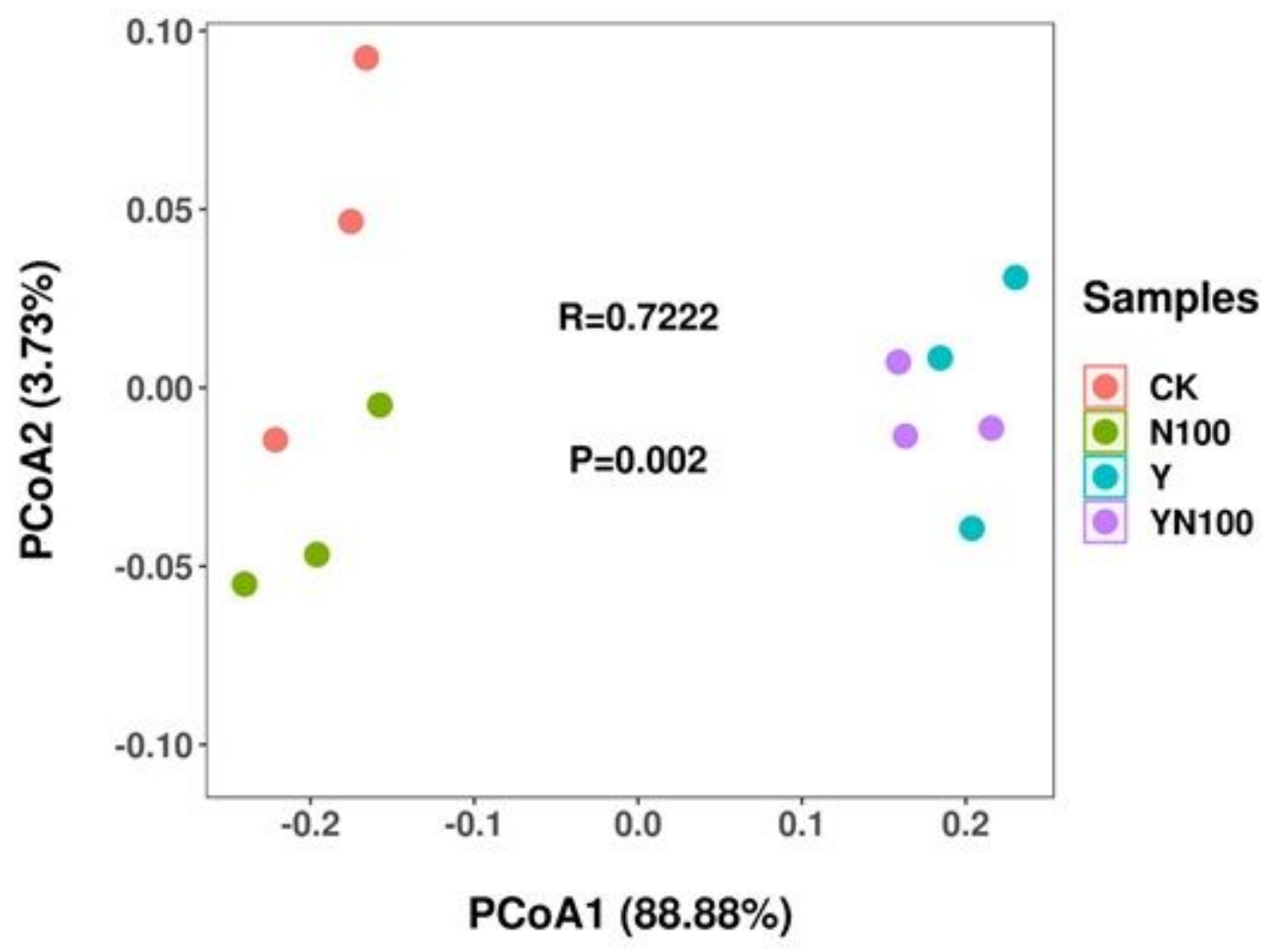

Figure 3

Principal coordinates analysis (PCoA) of bacterial communities in PAHs-contaminated soils under different treatments. CK: no citric acid and no corn straw addition; N100: soil amended with $100 \mathrm{mg} \cdot \mathrm{kg}-1$ citric acid; Y: soil amended with $5 \%$ corn straw; YN100: soil amended with $5 \%$ corn straw and $100 \mathrm{mg} \cdot \mathrm{kg}$ 1 citric acid. 


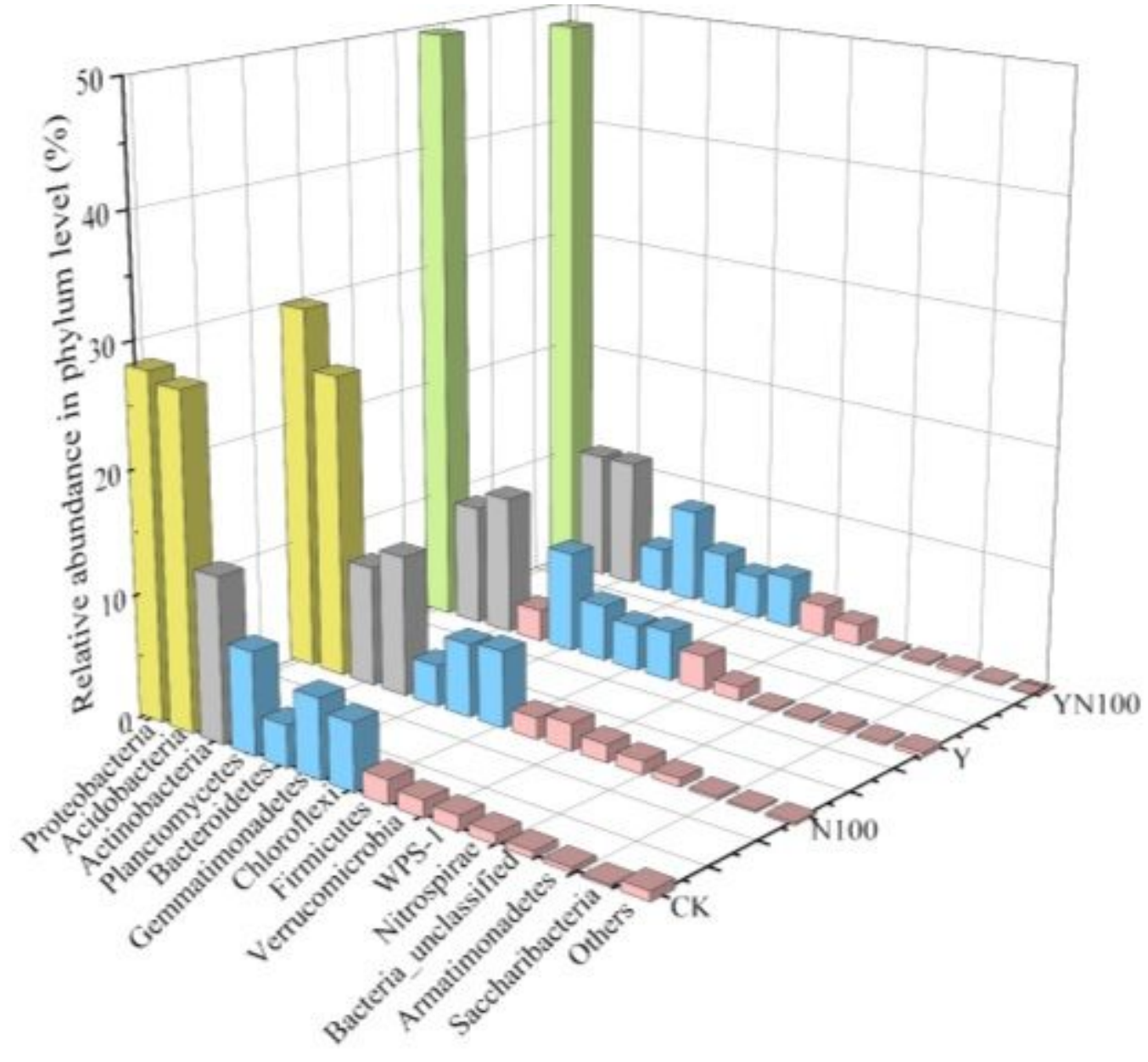

Figure 4

Relative abundances of bacterial phylum in PAHs-contaminated soils under different treatments after 28 days of incubation. CK: no citric acid and no corn straw addition; N100: soil amended with $100 \mathrm{mg} \cdot \mathrm{kg}-1$ citric acid; Y: soil amended with $5 \%$ corn straw; YN100: soil amended with $5 \%$ corn straw and $100 \mathrm{mg} \cdot \mathrm{kg}$ 1 citric acid. 


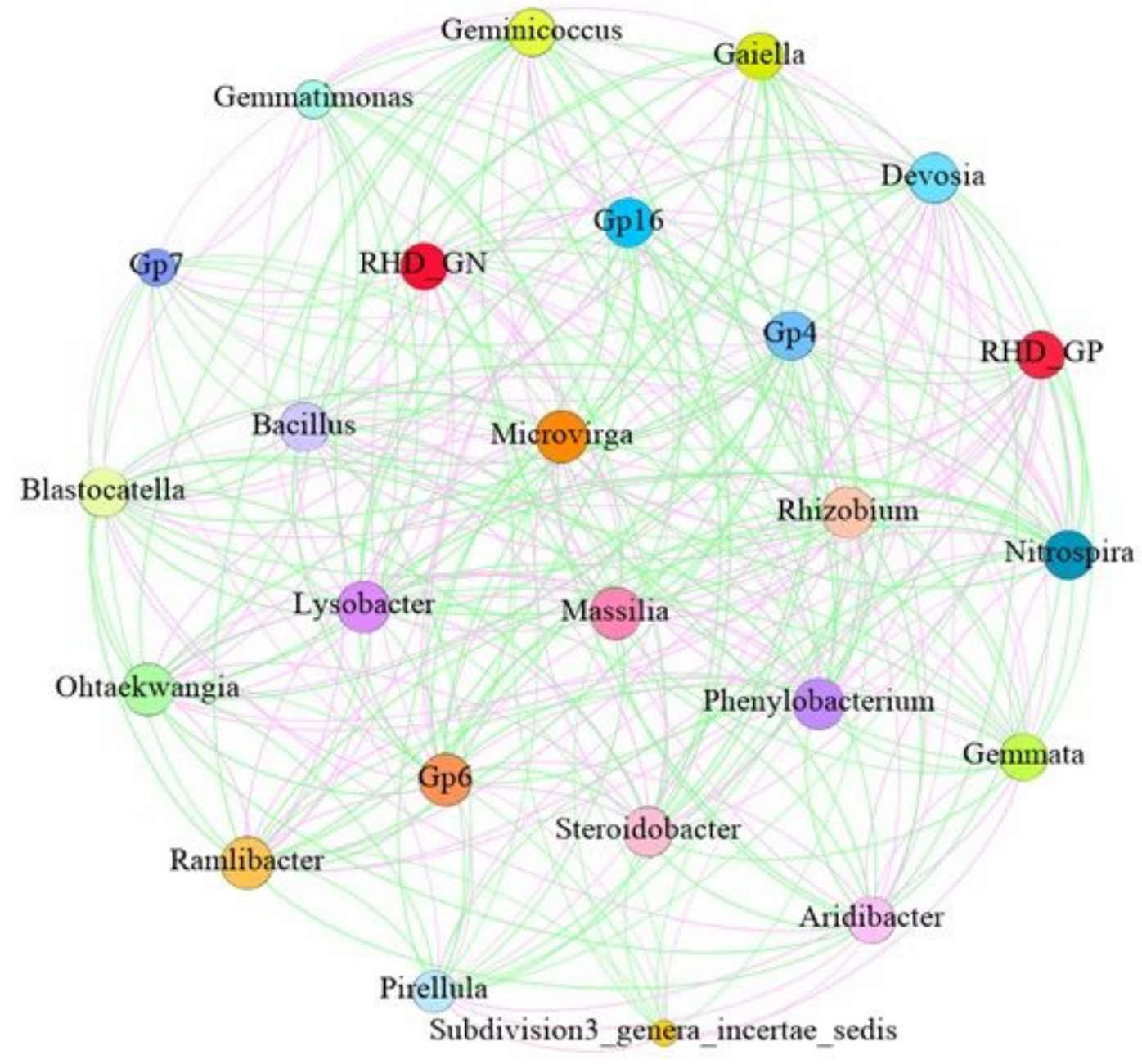

\section{Figure 5}

Network analysis based on the co-occurrence of PAH-RHDa genes and their potential host bacteria. A connection represents a significant positive (purple line) or (green line) correlation $(p<0.05)$ according to Spearman's rank analysis. 


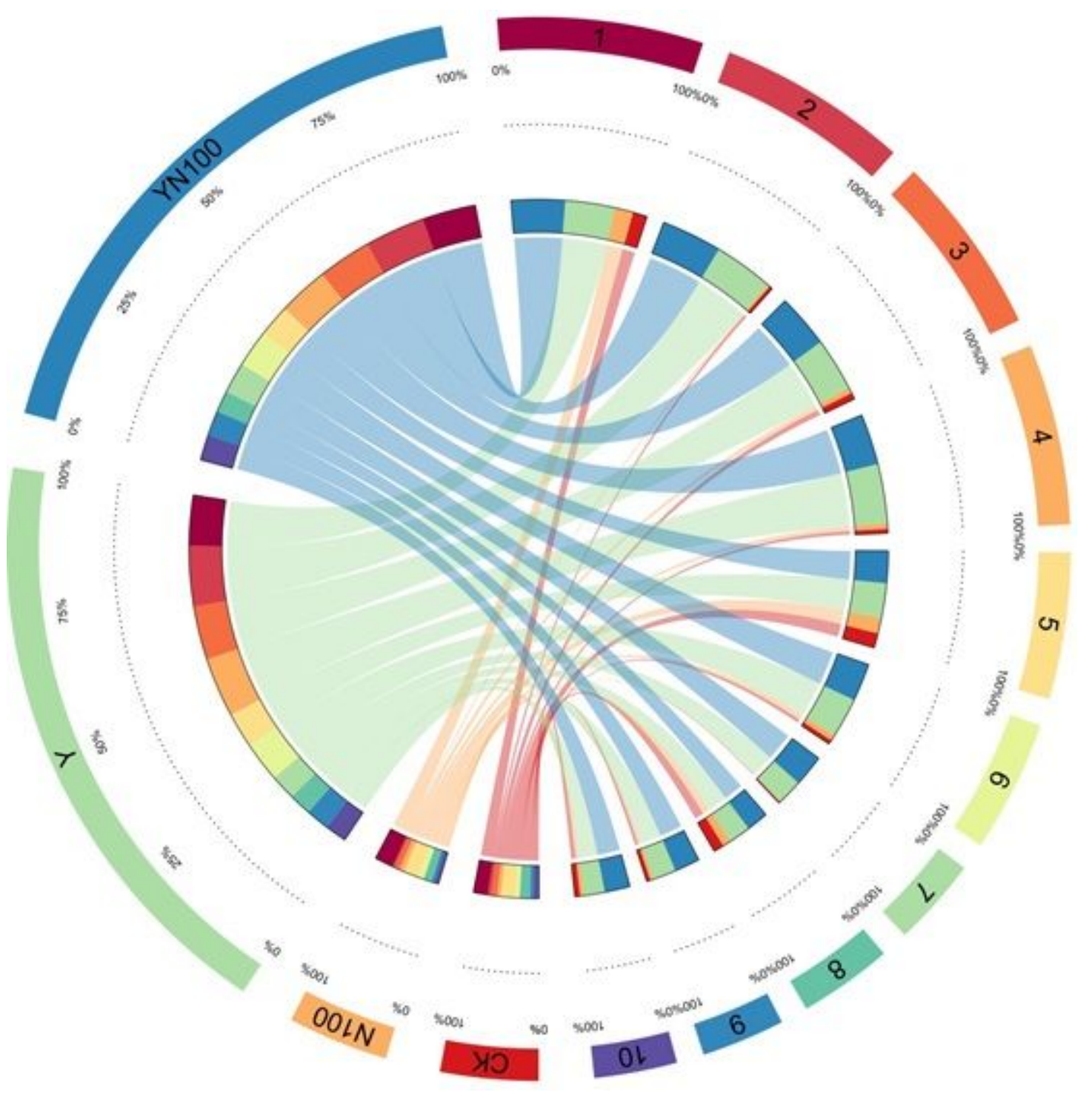

Figure 6

Changes in the relative abundances of PAHs degrader genus in PAHs-contaminated soils under different amendment treatments during 28 days of incubation. 1: Lysobacter; 2: Rhizobium; 3: Bacillus; 4: Devosia; 5: Ohtaekwangia; 6: Ramlibacter; 7: Massilia; 8: Steroidobacter; 9: Phenylobacterium; 10: Microvirga. 


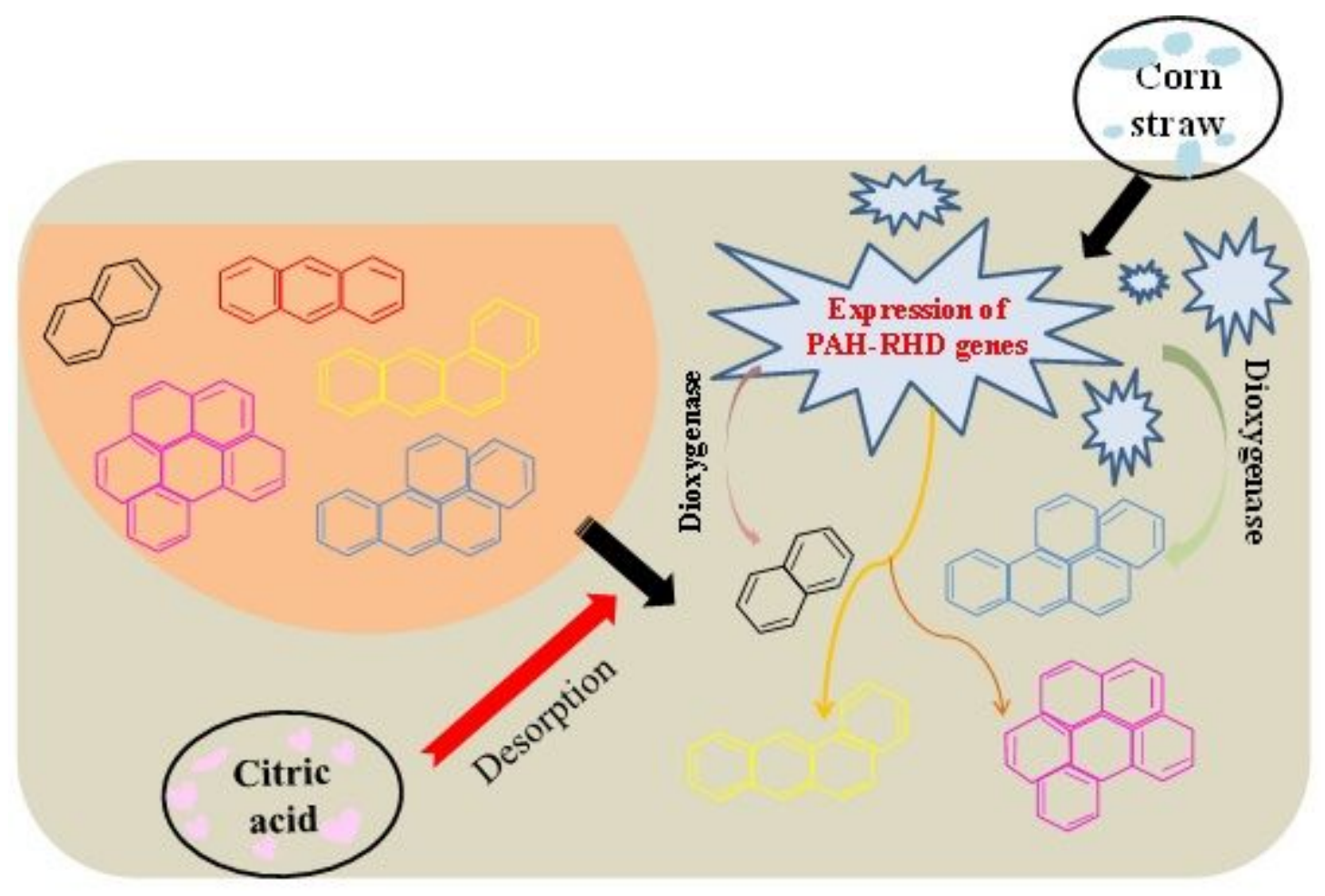

\section{Soil organic matter $\sum_{2 m}^{2 m}$ PAHs degraders $\square$ Soil}

Figure 7

The possible degradation mechanism of PAHs in soil treated with corn straw and citric acid.

\section{Supplementary Files}

This is a list of supplementary files associated with this preprint. Click to download.

- Supplementarydata.docx 